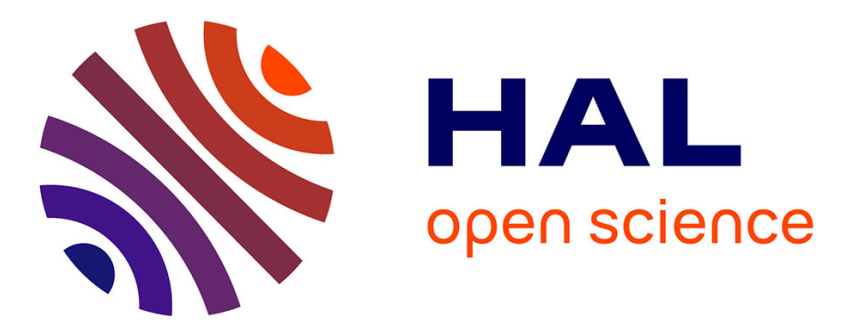

\title{
Life-history phenology strongly influences population vulnerability to toxicants: a case study with the mudsnail Potamopyrgus antipodarum.
}

Romain Coulaud, Jacques Mouthon, Hervé Quéau, Sandrine Charles, Arnaud Chaumot

\section{To cite this version:}

Romain Coulaud, Jacques Mouthon, Hervé Quéau, Sandrine Charles, Arnaud Chaumot. Life-history phenology strongly influences population vulnerability to toxicants: a case study with the mudsnail Potamopyrgus antipodarum.. Environmental Toxicology and Chemistry, 2013, 32 (8), pp.1727-36. 10.1002/etc.2235 . hal-00972342

\section{HAL Id: hal-00972342 https://hal.science/hal-00972342}

Submitted on 16 May 2020

HAL is a multi-disciplinary open access archive for the deposit and dissemination of scientific research documents, whether they are published or not. The documents may come from teaching and research institutions in France or abroad, or from public or private research centers.
L'archive ouverte pluridisciplinaire HAL, est destinée au dépôt et à la diffusion de documents scientifiques de niveau recherche, publiés ou non, émanant des établissements d'enseignement et de recherche français ou étrangers, des laboratoires publics ou privés. 
1 Life-history phenology strongly influences population vulnerability to toxicants: a case

2 study with the mudsnail Potamopyrgus antipodarum

3

4 Authors:

5 Romain Coulaud $^{\S \#}$, Jacques Mouthon ${ }^{\S}$, Hervé Quéau ${ }^{\S}$, Sandrine Charles ${ }^{\# \propto}$, Arnaud Chaumot ${ }^{\S £}$

6

7 affiliations:

$8 \S^{\S}$ Irstea, UR MALY, F-69626 Villeurbanne, France.

9 \# Université de Lyon, F-69000, Lyon ; Université Lyon 1 ; CNRS, UMR5558, Laboratoire de

10 Biométrie et Biologie Evolutive, F-69622 Villeurbanne, France.

$11{ }^{a}$ Institut Universitaire de France, 103, bd Saint-Michel, 75005 Paris, France. 
Abstract

One of the main objectives of ecological risk assessment is to evaluate the effects of toxicants on ecologically relevant biological systems such as populations or communities. However, the effects of toxicants are commonly measured on selected sub-individual or individual endpoints due to their specificity against chemical stressors. Introducing these effects into population models is a promising way to predict impacts on populations. Yet currently employed models are very simplistic and their environmental relevance needs to be improved to establish the ecological relevance of hazard assessment. This study with the gastropod Potamopyrgus antipodarum combines a field experimental approach with a

21 modelling framework. It clarifies the role played by seasonal variability of life-history traits in 22 the population's vulnerability to the alteration of individual performance, potentially caused 23 by toxic stress. The study comprised three steps: (i) characterization of the seasonal variability of the life-history traits of a local population over 1 year with in situ experiments on caged snails, coupled with a demographic follow-up, (ii) development of a periodic matrix population model which visualizes the monthly variability of population dynamics, and (iii)

27 simulation of the demographic consequences of an alteration of life-history traits (i.e., 28 fertility, juvenile and adult survival). The results revealed that demographic impacts strongly depend on the season when alterations of individual performance occur. Model analysis showed that this seasonal variability of population vulnerability is strongly related to the

31 phenology of the population. We underline that improving the realism of population models is 32 a major objective for ecological risk assessment, and that taking into account species 33 phenology in modelling approaches should be a priority.

Keywords (limit 5 keywords):

Phenology, life-history, in situ caging, ecological risk assessment, population modelling 


\section{Introduction}

Biological effects of toxicants are most frequently assessed in terms of alteration of sub-individual or individual performance (e.g., biomarkers) by means of bioassays or field monitoring. Nevertheless, for ecological risk assessment, these impacts on populations, communities and ecosystems are of primary concern [1-8]. Unfortunately, supplying an ecologically relevant assessment by measuring toxic impacts directly on these complex integrated systems is challenging, particularly because distinguishing toxicant impacts from the effects of other environmental factors or anthropogenic stressors can be difficult. One alternative methodology links the effects observed on individual-level endpoints measured in toxicity tests (in the laboratory or during in situ experiments) to impacts on populations [911]. However, a major problem is the complex relationship between the effects measured at the individual level and outcomes occurring at the population level [12-14]. Introducing the effects of toxicants on demographic parameters (i.e., related to life-history traits) into population models is one way to investigate this relation and to anticipate impacts at the

51 population level [10, 15-16]. In fact, such mechanistic ecological models provide a 52 quantitative way of integrating multiple individual-level endpoints, including survival, growth 53 and reproduction, in projections of population-level consequences such as changes in 54 population abundance or growth rate [17].

A large number of studies have demonstrated the value of using demographic models in an ecotoxicological context (reviewed in Galic et al. 2010). However, despite attempts to 57 use more elaborate modelling approaches that integrate environmental complexity [18-23], 58 the ecological relevance of the population models involved is generally low. In fact, in the great majority of studies, demographic models are based on laboratory assays with species that are not representative of the ecosystems of interest (e.g. tropical fishes or daphnids for

61 studies on lotic and temperate systems). These models are popular and useful tools for 
62 isolating the effects of a toxicant on the population growth rate [7], but they could fail to understand what occurs in the field on local populations [24]. In fact, the determinants of demographic sensitivity of populations are subject to strong variability (e.g., interspecies and interpopulation variability of life cycle). This variability cannot be taken into account with overly simple demographic models $[6,18,25-26]$. Notably, these models do not capture the

67 seasonal variability of population dynamics, even though several studies have underlined a seasonal variability of population vulnerability. A study on the crustacean amphipod Corophium volutator [27] showed that the same level of mortality impacts the population monthly variability of the sensitivity of the population growth rate to the different life-history traits. Thus, we need to develop population models which can integrate the seasonal variability of population dynamics to propose a more ecologically relevant assessment of the impact of toxicants on freshwater populations. caging and demographic follow-up) with a modelling framework (periodic matrix model) to decipher the role of seasonality in the vulnerability of populations to toxicants. The model organism is the widespread mudsnail Potamopyrgus antipodarum (Gray). We selected this species due to its sensitivity to a large range of chemicals for ecotoxicological tests in the

81 laboratory [30-34] or in the field [35-36]. Notably, P. antipodarum is proposed to the

82 Organization for Economic Cooperation and Development (OECD) as a relevant test species 83 to assess the impacts of endocrine disruptors on freshwater molluscs [37]. In the first step we 84 characterized the seasonal variability of the life-history traits of a population of $P$. antipodarum over 1 year, with experiments on caged snails and a demographic follow-up of the population. In the second step, we developed periodic matrix population models which 
87 allowed us to describe the demographic changes of this population and to picture the monthly

88 variability of its dynamics. In the third step, we simulated the demographic consequences for this population of an alteration of life-history traits (e.g., reduction in fertility, juvenile or adult survival), in order to illustrate the importance of the seasonal variability of population dynamics for ecological risk assessment of chemicals.

92

\section{Material and methods}

2.1. Biological data

$P$. antipodarum is a deposit-feeding gastropod which in Europe reproduces mainly by parthenogenesis of female populations [38]. We conducted a battery of experiments on a population on the Upper Rhône, in the Villebois reservoir $\left(05^{\circ} 27^{\prime} 55.3 \mathrm{E} ; 45^{\circ} 46^{\prime} 30.7 \mathrm{~N}\right.$, Rhône, France). This site was selected because it contains durable populations of freshwater molluscs monitored for more than one decade [39] and because it was accessible all year round (the water-level fluctuations do not exceed $0.50 \mathrm{~m}$ during the year). Temperature was continuously recorded every $2 \mathrm{~h}$ using the Tinytag Aquatic $2^{\circledR}$ temperature logger.

To characterize the different life-history traits and the population dynamics of $P$.

103 antipodarum, we used an in situ approach. Firstly, we conducted experiments with snails caged on the study site at different seasons for life-history trait quantification: fertility (i.e., number of neonates produced per reproductive female per day) and growth (i.e., increase of

107 based on a monthly population census to estimate the time-course in population 108 characteristics: densities, SL structure and fecundity (i.e., number of embryos in the brood 109 pouch). 
In situ caging experiments were conducted from October 2009 to November 2010 during 10 campaigns lasting 21 days. We measured contrasted environmental conditions between the different campaigns. In this way, mean water temperature, which is known to strongly influence $P$. antipodarum life-history traits [40-43], varied from 4.6 to $22.7^{\circ} \mathrm{C}$. We focused our experiments on measuring fertility and growth. During the year, we were able to study fertility during eight campaigns (insufficient numbers of adults during winter) and growth during seven campaigns (insufficient numbers of juveniles during three campaigns in summer and autumn). Snails were sampled and calibrated (i.e., size selection) directly at the study site. Initial SL was measured each time with a sample of 30 snails. SL was measured

121 between the apex and the distal extremity of the aperture under the binocular microscope, which corresponded to the maximal height of the shell. Initial SL varied from $2.28( \pm 0.16)$ $\mathrm{mm}$ to $2.85( \pm 0.34) \mathrm{mm}$ for juveniles and from $4.38( \pm 0.22)$ to $4.68( \pm 0.34)$ for adults between the different campaigns.

Four replicates of 30 juveniles and four replicates of 50 adults were used for growth and fertility measurement. Snails were placed in polypropylene cylindrical containers 127 (diameter, $10 \mathrm{~cm}$; length, $12 \mathrm{~cm}$ ) with pieces of net (mesh size, $100 \mu \mathrm{m}$ ) on perforations to 128 allow water flow. Because $P$. antipodarum lives in the upper layers of the sediments [41], a 2$\mathrm{cm}$ layer of sediment removed from the study site and sieved at $315 \mu \mathrm{m}$ (i.e., keeping out autochthonous snails) was added to the containers. Two containers with sediment but without

131 snails were deployed for each campaign as control of the absence of autochthonous snails. 132 Finally, containers were placed in a perforated protective case in polyvinylchloride (PVC) 133 with fixing elements for the containers. The containers were placed on the bottom of the river, 134 in close proximity to the site used for the demographic follow-up (see below) at a depth about $1.2 \mathrm{~m}$. After the 21-day exposure period, juveniles and adults were fixed with $20 \%$ alcohol and measured in the laboratory in order to estimate the snails' daily growth rates. Neonates 
137 laid during the period were also fixed with $20 \%$ alcohol and counted under a binocular

138 microscope. Then we estimated the fertility rates $b$ (i.e., number of neonates produced by

139 snail per day) as follows:

140

$b_{i}=\frac{n_{i}}{\left(\left(l_{i, 0}+l_{i, t}\right) / 2\right) \times t}$

141 where $b_{i}$ corresponds to the fertility rate of the replicate $i ; n_{i}$ to the number of neonates laid in

142 the replicate $i$; $t$ is the duration in days of the experiment (here $t=21$ days for all assays); $l_{i, 0}$

143 and $l_{i, t}$ are the number of living snails at the start and at the end of the experiment (here $l_{i, 0}=$

14450 for all assays).

2.1.2. Demographic follow-up

A monthly demographic follow-up was performed from October 2009 to November

2010. For each month, snails were sampled in four stations along a 300-m transect at a depth

149 from 0.50 to $1.5 \mathrm{~m}$ using a rectangular hand-net $(25 \times 18 \mathrm{~cm})$; the total area sampled was 1 $\mathrm{m}^{2}$. Samples were fixed on-site in $20 \%$ alcohol. Then we measured the SL of the snails present in a sub-sample corresponding to 9 out of 25 of the total sample in order to estimate monthly population densities and SL distributions. Considering 5\% percentiles in SL 153 distribution of juveniles, reproductive individuals and total individuals, we also determined,

154 for each month, SL at birth, SL at maturity and maximum SL to provide guidance in the 155 choice of the model's size classes. To estimate SL at maturity, we dissected 30 individuals covering a large range of sizes, and we counted the number of embryos in the brood pouch

157 (i.e., fecundity) according to the methodology described in Duft et al. [44]. This measurement 158 also allowed us to calculate a relationship between SL and fecundity and to estimate the 159 percentage of reproductive individuals for each adult class defined in the model. 
2.2. Modelling framework and demographic analysis

\subsubsection{Definition of the population model}

We used a periodic Lefkovitch matrix population model with five size classes [15, 45] to capture the dynamics of the P. antipodarum population. Periodic matrix models [46-47] are

often used to study cyclical temporal variation (e.g., seasonal or interannual) operated within

a single projection interval. The models take the form of periodic matrix products. We used size class models, in contrast to most ecotoxicological studies in which age class (Leslie models) or stage class models are employed [16]. We explain this choice with the following

170 arguments: (i) a valid method does not exist to determine the age of snails in field populations

171 for this species, (ii) we observed a strong correlation between SL and the life-history traits of 172 P. antipodarum (growth rate, maturity, fecundity) and (iii) in highly variable environments 173 (e.g., contrasted seasonality), the life-history of individuals in such short-living species 174 strongly depends on their date of birth, which makes age a very weak predictor of biological 175 features. This model thus distinguishes two classes of juveniles (J1 and J2) and three classes 176 of adults (A1, A2 and A3). It integrates the heterogeneity of vital rates (survival, growth and 177 fecundity) between size classes throughout the year.

178 Let $n_{i}(k)$ be the number of individuals of size class $i$ ( $i=1$ for $\mathrm{J} 1, i=2$ for $\mathrm{J} 2, i=3$ for $179 \mathrm{~A} 1, i=4$ for A2 and $i=5$ for A3) at the beginning of month $k$. The five $n_{i}(k)$ can be gathered 180 in a population vector $\mathbf{n}(k)$. Then we can define 12 monthly matrices $\mathbf{M}_{k}$ which link up the

181 population vectors $\mathbf{n}(k)$ between months $k$ and $k+1$ as follows:

$$
\mathbf{n}(k+1)=\mathbf{M}_{k} \mathbf{n}(k)
$$

183 with: 


$$
\mathbf{M}_{k}=\left[\begin{array}{ccccc}
s_{1}(k)\left(1-\sum_{j>1} g_{1, j}(k)\right) & 0 & f_{3}(k) \sqrt{s_{1}(k)} \sqrt{s_{3}(k)} & f_{4}(k) \sqrt{s_{1}(k)} \sqrt{s_{4}(k)} & f_{3}(k) \sqrt{s_{1}(k)} \sqrt{s_{5}(k)} \\
s_{1}(k) g_{1,2}(k) & s_{2}(k)\left(1-\sum_{j>2} g_{2, j}(k)\right) & 0 & 0 & 0 \\
s_{1}(k) g_{1,3}(k) & s_{2}(k) g_{2,3}(k) & s_{3}(k)\left(1-\sum_{j>3} g_{3, j}(k)\right) & 0 & 0 \\
s_{1}(k) g_{1,4}(k) & s_{2}(k) g_{2,4}(k) & s_{3}(k) g_{3,4}(k) & s_{4}(k)\left(1-g_{4,5}(k)\right) & 0 \\
s_{1}(k) g_{1,5}(k) & s_{2}(k) g_{2,5}(k) & s_{3}(k) g_{3,5}(k) & s_{4}(k) g_{4,5}(k) & s_{5}(k)
\end{array}\right]
$$

185 where $s_{i}(k)$ is the survival rate of the size class $i$ during month $k, g_{i, j}(k)$ the transition rate 186 between the size classes $i$ and $j$ during month $k$, and $f_{i}(k)$ the reproductive rate of the size 187 class $i$ during month $k$. The product of the 12 monthly matrices $\mathbf{M}_{k}$ leads to an annual 188 periodic matrix $\mathbf{L}$, which links the population vector from year $t$ to year $t+1$ as follows:

$$
\mathbf{n}(t+1)=\left(\prod_{k=1}^{12} \mathbf{M}_{k}\right) \mathbf{n}(t)=\mathbf{L} \mathbf{n}(t)
$$

To assess the seasonal variability of the demographic sensitivity of the population, we also defined four seasonal periodic matrices: $\mathbf{L}_{\mathbf{A}}$ for autumn, $\mathbf{L}_{\mathbf{W}}$ for winter, $\mathbf{L}_{\mathbf{S P}}$ for spring and $\mathbf{L}_{\mathbf{S U}}$ for summer. These matrices correspond to the product of the three monthly matrices $\mathbf{M}_{k}$ corresponding to each season (i.e., September, October and November in autumn; December, January and February in winter; March, April and May in spring; and June, July and August in summer).

\subsubsection{Parameter estimation} and 5) as follows:

$$
f_{i}(k)=b_{i}(k) \rho_{i}(k) \Delta t(k)
$$

201 where $b_{i}(k)$ corresponds to fertility (i.e., number of neonates produced by reproductive female

202 per day) for class $i$ during month $k, \rho_{i}(k)$ to the percentage of females in reproduction in class $203 i$ during month $k$, and $\Delta t(k)$ to the number of days of month $k . \rho_{i}(k)$ was estimated with data 
204 from the demographic follow-up (see above), and $b_{i}(k)$ was predicted with the mean monthly water temperature, according to the relationship between mean temperature and fertility established from outcomes of caging experiments. Because only one size class of adults was

207 used for in situ caging, we controlled the size effect between classes in the calculation of $b_{i}(k)$

208 using the relationship between SL and fecundity (i.e., number of embryos in the brood 209 pouch), which is established from the demographic follow-up. Similarly, we calculated the 210 transition rates $g_{i, j}(k)$ using the relationship between growth and temperature estimated in in 211 situ caging experiments. Using the mean water temperature recorded during month $k$, we 212 predicted the growth of individuals with size at the limits of each class $i$ between months $k$ 213 and $k+1$, and then we estimated for each size class the proportion of individuals which stayed in size class $i$, or which attained the larger size classes.

It is not possible to estimate the survival rates directly from field experiments. In fact, mark and recapture methodologies, which are currently used for larger organisms (e.g., fish, 217 mammals) are not easy to set up for $P$. antipodarum due to the difficulty marking the snails durably. Alternatively, the survival rates observed with the caged snails were not ecologically relevant (e.g., lack of predation, competition). Therefore, to estimate the survival rates of individuals for a month $k$, we compared the densities observed during the demographic

221 follow-up in month $k$ to the theoretical densities predicted by the observed densities of month $k-1$ and the growth and reproductive rates of the individuals estimated for month $k-1$.

2.2.3. Model outcomes, elasticity analyses and simulations

226 Leslie matrix. It presents a first dominant eigenvalue $\lambda$, corresponding to the asymptotic 227 population growth rate $[15,48]$. The right eigenvector $\mathrm{w}$ associated with this first eigenvalue 228 gives the asymptotic stable size structure. According to the first matrix used in the matricial 
229 product of the 12 monthly matrices $\mathbf{M}_{k}$, we can obtain the different SL structures at the end

230 of each month of the year. The demographic elasticities were analyzed by simulation with the

231 application of $10 \%$ reduction in each life-history trait successively (i.e., survival of each class,

232 fertility and growth) in order to estimate the subsequent relative reduction in the asymptotic

233 population growth rate $\lambda$. To examine the between-season variability of population

234 vulnerability, we also simulated the demographic consequences of different levels of

235 alteration of life-history traits at different dates in the year. To accomplish this, reductions

236 from $0 \%$ to $100 \%$ on fertility, juvenile survival and adult survival were applied to the three

237 months corresponding to each season.

238

2.3. Statistical analyses

Statistical procedures and population models were all implemented with the $\mathrm{R}$

241 software [49]. Before using parametric analysis (ANOVA procedure), normality and

242 homoscedasticity were checked using the Shapiro-Wilk test and the Bartlett test, respectively.

243 To quantify growth of $P$. antipodarum snails in in situ caging, we fitted, independently for 244 each caging experiment, a logistic model on SL data using the $n l s$ function, simultaneously

245 considering the two categories of caged snails (juveniles and adults) as follows:

$$
L(t)=\frac{\text { Lmax }}{1+\left(\frac{\text { Lmax }}{\text { Linit }}-1\right) e^{(-r t)}}
$$

247 where $L(t)$ corresponds to the SL of snails at time $t$, Lmax to the maximal SL of snails

248 observed in the population, Linit to the SL of the two categories of caged snails at the

249 beginning of the experiment, $r$ to the daily growth coefficient of the logistic model, and $t$ to 250 the time. We fixed $\operatorname{Lmax}$ at $5.5 \mathrm{~mm}$ (maximum value observed during the demographic 251 follow-up). No replicate effect was considered when fitting the logistic models (one per 252 campaign), since no significant difference in SL of juveniles and adults were detected 
253 between replicates at the end of the test for each one of the seven campaigns. Concerning the

254 seasonal variability of fertility and daily growth, we fitted Gaussian relationships between

255 these life-history traits and water temperature using the $n l s$ function. For the demographic

256 follow-up, the influences of SL and month on fecundity were tested using linear modelling

257 including the interaction terms (ANOVA procedure).

258

259

3. Results

260

261

3.1. Seasonal variability of life-history traits

262

By means of in situ caging experiments, we recorded strong seasonal variability in the

263 production of $P$. antipodarum neonates, which varied from 0 to 0.8 neonates per female per

264 day. This seasonal variability in fertility was highly correlated with water temperature (Figure

$2653 \mathrm{~A}$ ). Thus, we fitted a Gaussian curve to describe fertility $b_{i}$ (production of neonates per day

266 per reproductive female) as a function of mean water temperature $\theta$ (in ${ }^{\circ} \mathrm{C}$ ) as follows:

267

$$
b_{i}(\theta)=6.92 \times e^{\left(\frac{17.91-\theta}{3.85}\right)^{2}}
$$

268 Fertility is optimal at a temperature of $17.91{ }^{\circ} \mathrm{C}$. Concerning growth, here again we detected

269 strong seasonal variability of individual SL gains, in relation with the mean water temperature

270 (Figure 3B). We used nonlinear regression to fit a Gaussian relationship between growth

271 coefficient $r$ and mean water temperature $\theta$ (in ${ }^{\circ} \mathrm{C}$ ) as follows:

$$
r(\theta)=0.006+0.21 \times e^{\left(\frac{18.61-\theta}{3.72}\right)^{2}}
$$

273 In comparison with fertility, we added a constant parameter in order to take into account a

274 minimal daily growth rate different from 0 . In fact, contrary to fertility, which was null during 
275 the caging with the lower temperature (Figure 3A), we observed that individuals grow even at

276 low temperatures (Figure 3B). Growth is optimal at $18.61^{\circ} \mathrm{C}$.

277 Concerning the monthly demographic follow-up, the evolution of the population's SL

278 structure is presented in Figure 1. The highest densities were observed in autumn (e.g., more

279 than 10,000 individuals per square metre in October and November) and the lowest in spring.

280 Juveniles (i.e., SL $<3.5 \mathrm{~mm}$, size classes $\mathrm{J} 1$ and $\mathrm{J} 2$ of the model) are present throughout the

281 year and account for the major part of the population, while adult densities (i.e., $\mathrm{SL}>3.5 \mathrm{~mm}$,

282 size classes A1, A2 and A3) show highly variable frequencies during the year. In fact, in

283 winter and spring, the population comprises mainly juveniles, while in summer and autumn

284 adults appear in the population. We estimated a SL at birth of $0.5(0.1) \mathrm{mm}$, a SL at maturity 285 of $3.5(0.2) \mathrm{mm}$ and a maximum SL of $5.2(0.3) \mathrm{mm}$. According to these very weak standard 286 deviations, we did not consider monthly differences in the SL at birth, at maturity and the maximum SL for the parameterisation of the population model. Concerning the percentage of individuals in reproduction (i.e., females bearing embryos) $\rho_{i}(k)$, for all dates of the year, 289 more than $90 \%$ of the individuals with a SL greater than $4.2 \mathrm{~mm}$ were reproductive. 290 Individuals between 3.5 and $4.2 \mathrm{~mm}$ presented a seasonal variability: $50 \%$ of individuals were 291 reproductive between November and May and 80\% between June and October. We observe a 292 strong positive relationship between SL and fecundity (Figure 2), with no seasonal effect 293 (ANOVA test: interaction terms, $p>0.1$; seasonal effect, $p>0.81$; SL effect, $p<10^{-15}$ ). In 294 this way, we note that females of the model's A1 size class have a mean fecundity of 12.2 295 embryos; size class A2 females a mean fecundity of 24.3 embryos and size class A3 females a mean fecundity of 37.6 embryos. 
Regarding parameter estimation, we report a strong between-class and between-month variability of the reproductive rates $f_{i}(k)$. Between November and March, reproductive rates

were very low for all classes due to low water temperatures, while all size classes reproduced

302 between April and October. Depending on the size class and the month, reproductive rates varied from 0.01 to 35.05 neonates per month per individual. Regarding the transition rates $g_{i, j}(k)$, the majority of individuals stayed in their initial size class from month to month during winter and spring, in contrast to summer and autumn, where growth was faster and a great majority of individuals changed one or two size classes over 2 months. Adult survival showed high monthly variability with very low survival rates between January and May and higher survival rates in summer and autumn. Juvenile survival (for size classes J1 and J2) was generally higher than adult survival, particularly in winter and spring. For some months, we calculated survival rates higher than 1 , in particular when densities of individuals were low

311 (uncertainty increased with small size samples). For the parameterization of the matrix model, we tested two possibilities: (i) we applied the survival rates keeping the values higher than 1 313 (apparent survivals), or alternatively (ii) we fixed a ceiling level of 1 for maximum survival 314 rates. Despite differences in the absolute value of the asymptotic population growth rate $\lambda$, the stable size distribution and elasticity pattern were very similar in both cases. For the following results on model analysis, we chose to use survival rates capped at 1 , but conclusions on the demographic behaviour of the population remain unchanged with apparent survival rates. In a first time, we calculated the asymptotic population growth rate $\lambda$ with the annual

319 periodic matrix $\mathbf{L}$. We found a value of $\lambda=1.17$. We also computed the stable size 320 distribution for the different seasons that we compared to the population structure observed 321 during the demographic follow-up (Figure 4). We noted good coherence between the model and the field data. Thus, it appears that our mechanistic modelling framework can identify the dynamics of the $P$. antipodarum population throughout the year. In a second time, we 
324 characterized the seasonal variability of the demographic fitness of the population by

325 calculating the asymptotic population growth rate of the four periodic seasonal matrices $\left(\mathbf{L}_{\mathbf{A}}\right.$,

$326 \mathbf{L}_{\mathbf{W}}, \mathbf{L}_{\mathbf{S P}}$ and $\mathbf{L}_{\mathbf{S U}}$ ). We found 3-month $\lambda$ values equal to 1.02 in autumn, 0.17 in winter, 0.16

327 in spring and 2.31 in summer. For comparison to the annual matrix $\mathbf{L}$, the standardization of

$328 \lambda$ to a 3-month time step supplies a value of 1.04. Thus, we underline a strong seasonal

329 variability of snail population dynamics, with a potential growth of the population mainly in

330 summer and autumn.

331 The elasticity analysis on the annual matrix $\mathbf{L}$ showed that the asymptotic population 332 growth rate $\lambda$ was more sensitive to relative changes in juvenile survival (S1 and S2) than to 333 changes in the other life-history traits (Figure 5). The life-history trait corresponding to the 334 second highest elasticity was adult survival (cumulative elasticities of S3, S4 and S5) 335 followed by fertility. Concerning growth (Figure 5), we observe that the population growth 336 rate was not sensitive to relative changes in this life-history trait. On the contrary, we note that 337 a reduction of the daily growth rates strikingly increases the asymptotic population growth 338 rate $\lambda$. We also performed elasticity analysis on the four seasonal matrices $\left(\mathbf{L}_{\mathbf{A}}, \mathbf{L}_{\mathbf{W}}, \mathbf{L}_{\mathbf{S P}}\right.$ and $339 \mathbf{L}_{\text {su }}$ ) (Figure 6). These analyses reveal two contrasted patterns. On one hand, in spring and 340 winter, the population growth rate was very sensitive to juvenile survival alteration but 341 remained unchanged by reduction in adult survival or reproduction rates. Concerning growth, 342 we observe, as for the annual model, that the reduction of this life-history trait increased the 343 asymptotic population growth rate. On the other hand, in summer and autumn, the population 344 growth rate was sensitive to changes in juvenile survival but also to changes in adult survival, 345 fertility and growth. 
that the population growth rate was highly affected for all seasons, concerning reproduction and adult survival, between-season differences were substantial. Indeed, the population was low sensitivity in spring and winter, even for substantial fertility inhibitions. Furthermore, the population was very sensitive to impacts on adult survival in summer, even for very small inhibitions, but quite insensitive in the other seasons even for considerable inhibitions.

\section{Discussion}

\subsection{Seasonal variability of life-history traits of $P$. antipodarum}

We observed fluctuating densities during the year. The high-density pattern at the end

360 of summer and autumn and the low-density pattern in winter and spring agree with previous 361 data obtained during demographic follow-up conducted for $P$. antipodarum [41, 50].

362 Furthermore, these density variations during the year are consistent with the observations of a 363 long-term follow-up of mollusc populations conducted in this study site (data not published 364 for P. antipodarum). However, Schreiber et al. [51] observed the highest densities in spring 365 and summer. This contrast with the present study can be explained by the delaying effect of temperature rise due to a large snow-melt upstream of the Rhône watershed. For Richards and

367 Shin [52], these fluctuating densities are driven by density-dependent processes. Nevertheless, 368 in populations with small temperature fluctuations, Quinn et al. [53] observed that densities 369 are very stable during the year, and it is widely accepted that $P$. antipodarum population 370 densities are generally strongly correlated with water temperature [50], consistent with our 371 observations. The population in our case was primarily composed of juveniles, particularly in 372 winter and spring, which agrees with previous data [51, 54]. In this way, the persistence of the 373 population in winter is ensured by the survival of a reserve of juveniles. In summer and 
374 autumn, the population is composed of two cohorts, one with small juveniles and one with

375 large adults. The size at birth, size at maturity and maximum size values are consistent with 376 previous reports for this species [30, 51, 54-57]. Similar to Schreiber et al. [51], who observed $37765 \%$ reproductive females in their population, we observed that the majority of females 378 carried embryos. During dissections, we never observed males, as in other studies which 379 stated that the vast majority of European populations of $P$. antipodarum are made up of 380 parthenogenetic females [38] with a few exceptional males [58]. This explains why we did 381 not integrate the sex ratio into our model.

The methodology of in situ caging implemented here throughout the year provides a useful tool to estimate life-history traits in the field (e.g., realistic exposure conditions, good reproducibility of the assays) [59-60]. Until now, only a few studies have conducted in situ experiments with $P$. antipodarum $[35-36,61]$. Here, we chose this methodology rather than a laboratory approach in order to obtain environmentally relevant data for the calibration of the population model. In fact, several factors are difficult to control in laboratory conditions, in particular the diet of $P$. antipodarum. Here, we report a strong seasonal variability in neonate production and growth rates. Several studies have shown that $P$. antipodarum life-history traits are strongly correlated with water temperature [40, 42]. The quality of the fits observed in Figure 3 confirms this pattern. The maximum fertility value $(0.80$ juveniles per day recorded during caging at a mean temperature of $17.5^{\circ} \mathrm{C}$ ) is higher than the values reported in other studies for this temperature range [30-31]. Nevertheless, all the studies which measured

394 fertility directly (i.e., counting production of neonates) were conducted during laboratory 395 experiments, which probably do not offer optimal conditions for the reproduction of this species. To our knowledge, our study reports for the first time a direct in situ measurement of fertility. In fact, in in situ assays, fertility is usually estimated indirectly from fecundity (i.e., counting of the number of embryos in the brood pouch) $[35-36,61]$. This measure can 
provide useful information but it remains difficult to predict the realized reproduction of

400 individuals without information on laying dynamics. We estimated an optimal temperature of

$401 \quad 17.9^{\circ} \mathrm{C}$ for fertility. This value is consistent with previous laboratory studies [40, 42]. Schmitt

et al. [36] did not observe a relationship between temperature and fertility during different in

situ experiments, but the temperature range was very narrow compared to our experiments.

404 Concerning growth, we estimated an optimal value of $18.7^{\circ} \mathrm{C}$ close to the fertility value.

405 Thus, water temperature between 17 and $19^{\circ} \mathrm{C}$ appeared to provide optimal conditions for the development of P. antipodarum.

4.2. Demographic insights from the population model analysis

The adequacy of the stable size distribution computed for each season with the population size structure observed during the demographic follow-up (Figure 4) illustrates that our modelling framework is able to reliably describe the dynamics of this P. antipodarum population taking into account its particular phenology. The analysis of seasonal matrices $\left(\mathbf{L}_{\mathbf{A}}, \mathbf{L}_{\mathbf{W}}, \mathbf{L}_{\mathbf{S P}}\right.$ and $\left.\mathbf{L}_{\mathbf{S U}}\right)$, which simulate population dynamics under hypothetical scenarios of eternal autumn, winter, spring or summer, allows us to underline substantial seasonal variability in the demographic fitness of the population (quantified by the asymptotic growth rate $\lambda$ ). On one hand, winter and spring are seasons with a potential population decrease, and 417 on the other hand, summer and autumn seasons have a high potential for a population 418 increase. This is explained by reproductive rates that are nearly zero in spring and winter 419 along with very low survival rates, in particular for adults.

With the annual model, we observed that the population dynamics is particularly

421 sensitive to changes in juvenile survival (Figure 5). This is consistent with the conclusions of 422 several demographic studies on $P$. antipodarum [30, 34, 62]. Pedersen et al. [30], when 423 studying the effects of the polycyclic musk HHCB on individual and population-level 
424 endpoints, observed that the asymptotic population growth rate of $P$. antipodarum is

425 approximately four times more sensitive to juvenile survival alteration than to adult survival,

426 and ten times more sensitive to juvenile survival alteration than to fertility inhibition.

427 Surprisingly, we noted that a reduction of the daily growth rate increased the asymptotic

428 population growth rate $\lambda$. This unexpected demographic outcome can be explained by the very

429 low survival rates of the last classes of adults for several months in spring and winter. Thus,

430 when the daily growth rate is decreased, individuals stay for more months in the first class of

431 adults with higher survival rates, which increases their cumulative reproductive value for the population. This advantage for organisms with a low growth rate is similar to observations on

433 fish populations under fishing pressure, in which higher mortality rates lead to the selection of 434 individuals with lower growth ability [63-64]. With the seasonal models, we show an 435 important seasonal variability of the pattern of elasticities (Figure 6). In fact, in the same manner as for the population dynamics, we can identify two contrasted periods. In spring and

437 winter, the population is mostly sensitive to the reduction in juvenile survival, while in 438 summer and autumn, the demographic sensitivity to juvenile survival reduction is 439 considerably reduced, and the population demography becomes more sensitive to the 440 alteration of other traits. This strong seasonal variability of population sensitivity is explained 441 by the phenology of the population: in winter and spring, maintenance of the population is 442 ensured by a stock of juveniles (no reproduction, high adult mortality), whereas in summer 443 and autumn, juveniles grow up, mature as adults, and therefore reproduce. Seasonal 444 variability of population sensitivity is also observed in the amphipod Leptocheirus plumulosus 445 using a field-based periodic matrix population model [28-29]. Thus, analyzing the elasticity of 446 periodic matrix models can provide valuable insights into the relative importance of the 447 demographic rates at different periods of year. 
4.3. Seasonal variability and field-based population models in ecological risk assessment

Despite the substantial seasonal variability of population demographic sensitivity, to

451 our knowledge, only a few ecotoxicological studies have addressed the temporal variability of

452 effects on population dynamics [27-29]. We roughly simulated reductions in fertility, juvenile

453 survival and adult survival at different seasons. Population impacts strongly depend on the

454 season at which toxic effects on individual performance occur (Figure 7). For instance, a time

455 window of high population vulnerability to reproductive alteration is focused in summer and

456 autumn, in contrast to winter and spring, for juvenile mortality. Thus, the development of

457 population models that integrate seasonality is a relevant way to increase our ability to project

458 toxic effects on individual performance into population demographic impacts. As an

459 illustration, when studying HHCB effects on $P$. antipodarum, Pedersen et al. [30] observed

460 significant effects on offspring production up to $42 \%$ reduction) but stated that such

461 inhibitions will not give rise to significant impacts on population dynamics. In spring and

462 winter, our simulations agree with this conclusion. However, in summer and particularly in

463 autumn, we anticipate considerable population consequences of such levels of fertility

464 inhibition. In fact, in autumn, we observed that a $40 \%$ reduction in fertility means a $30 \%$

465 decrease of the asymptotic population growth rate (Figure 7). Similar to the great majority of 466 studies addressing population extrapolation, the life cycle is roughly parameterized from 467 laboratory data. In fact, life-history traits are often estimated in the controls of the 468 experiments and are not representative of life-history of local populations. Thus, with this 469 laboratory approach, models do not provide valuable information about potential 470 demographic consequences of toxicant impacts in field populations [30]. Laboratory 471 conditions are too favourable (e.g., no predation or competition, water temperature is 472 constant) or in contrast, they fail to provide optimal conditions or complexity for all abiotic 473 and biotic parameters (e.g., oxygenation, water flow, temperature, food, crowding effect). One 
474 way currently used to address such concerns about the ecological relevance of population

475 extrapolation consists in exploring a range of values of life-history traits and showing that

476 changes in the population growth rate are low. By this means, authors aim to assess the

477 robustness of their conclusions against divergence in life histories between laboratory and

478 wild populations. For example, Pedersen et al. [30] validated the robustness of their

479 population model by testing three scenarios: decrease in juvenile survival, decrease in

480 juvenile and adult survival, and decrease in juvenile survival, adult survival and fertility. But

481 the range of tested fluctuations is not at all "field-realistic" regarding our field observations:

482 (i) only $50 \%$ for fertility, whereas we showed in the $P$. antipodarum population that fertility is

483 very low during a great part of the year with greater reduction than in this study; and (ii) only

484 a 20\% reduction in adult survival and a 90\% reduction in juvenile survival, while we observed

485 that juvenile mortality is generally lower than adult mortality in the field. Thus, it appears that

486 a field-based approach can be of great interest to guarantee the relevance of hazard

487 assessment at the population level, and to provide realistic scenarios for exploring its

488 soundness with respect to between-population variability of life-histories.

489 Improving the ecological realism of population models is a major concern for

490 ecological risk assessment. Incorporating species phenologies is feasible with modelling

491 approaches and should be one priority when seeking to put the "eco into ecotoxicology" [2].

\section{Acknowledgments}

495 The authors thank the Cluster Environnement of the Région Rhône-Alpes (France) for 496 financial grants. 


\section{References}

498

499 [1] Barnthouse LW, Munns WR, Sorensen MT. 2008. Population-level ecological risk 500 assessment. SETAC.

501 [2] Chapman PM. 2002. Integrating toxicology and ecology: Putting the 'eco' into 502 ecotoxicology. Marine Pollution Bulletin 44:7-15.

503 [3] Forbes VE, Calow P, Grimm V, Hayashi TI, Jager T, Katholm A, Palmqvist A,

504 Pastorok R, Salvito D, Sibly R, Spromberg J, Stark J, Stillman RA. 2011. Adding value to 505 ecological risk assessment with population modeling. Human and Ecological Risk Assessment $506 \quad 17: 287-299$.

507 [4] Forbes VE, Calow P, Grimm V, Hayashi T, Jager T, Palmqvist A, Pastorok R, 508 Salvitoy D, Sibly R, Spromberg J, Stark J, Stillman RA. 2010. Integrating population 509 modeling into ecological risk assessment. Integrated Environmental Assessment and 510 Management 6:191-193.

511 [5] Forbes VE, Palmqvist A, Bach L. 2006. The use and misuse of biomarkers in 512 ecotoxicology. Environmental Toxicology and Chemistry 25:272-280.

513 [6] Landis WG. 2006. Population-scale assessment endpoints in ecological risk 514 assessment. Part I: Reflections of stakeholder values. Integrated Environmental Assessment 515 and Management 2:86-91. 
516 [7] Raimondo S, McKenney Jr CL. 2006. From organisms to populations: Modeling 517 aquatic toxicity data across two levels of biological organization. Environmental Toxicology 518 and Chemistry 25:589-596.

519 [8] Thorbek P, Forbes VE, Heimbach F. 2009. Ecological Models for Regulatory Risk 520 Assessments of Pesticides: Developing a Strategy for the Future. CRC Press.

521 [9] Levin L, Caswell H, Bridges T, Dibacco C, Cabrera D, Plaia G. 1996. Demographic 522 responses of estuarine polychaetes to pollutants: life table response experiments. Ecological 523 Applications 6:1295-1313.

524 [10] Forbes VE, Calow P. 2002. Extrapolation in Ecological Risk Assessment: Balancing 525 Pragmatism and Precaution in Chemical Controls Legislation. BioScience 52:249-257.

526 [11] Forbes VE, Calow P, Sibly RM. 2008. The extrapolation problem and how population 527 modeling can help. Environmental Toxicology and Chemistry 27:1987-1994.

528 [12] Widarto TH, Krogh PH, Forbes VE. 2007. Nonylphenol stimulates fecundity but not 529 population growth rate of Folsomia candida. Ecotoxicology and Environmental Safety 67:369530377.

531 [13] Kammenga JE, Busschers M, Van Straalen NM, Jepson PC, Bakker J. 1996. Stress 532 induced fitness reduction is not determined by the most sensitive life-cycle trait. Functional 533 Ecology 10:106-111. 
534 [14] Stark JD, Banks JE, Vargas R. 2004. How risky is risk assessment: The role that life

535 history strategies play in susceptibility of species to stress. Proceedings of the National 536 Academy of Sciences of the United States of America 101:732-736.

[15] Caswell H. 2001. Matrix Population Models. John Wiley \& Sons, Ltd.

538 [16] Galic N, Hommen U, Baveco JM, Van Den Brink PJ. 2010. Potential application of 539 population models in the european ecological risk assessment of chemicals II: Review of 540 models and their potential to address environmental protection aims. Integrated

541 Environmental Assessment and Management 6:338-360.

542 [17] Hanson N. 2011. Population Modeling of the Fish Species Roach (Rutilus rutilus) to 543 Investigate How Latitudinal Variations in Life History Traits Affect the Sensitivity to 544 Anthropogenic Stress. Environmental Modeling and Assessment:1-11.

545 [18] Ares J. 2003. Time and space issues in ecotoxicology: Population models, landscape 546 pattern analysis, and long-range environmental chemistry. Environmental Toxicology and 547 Chemistry 22:945-957.

548 [19] Chaumot A, Charles S, Flammarion P, Auger P. 2003. Do migratory or demographic 549 disruptions rule the population impact of pollution in spatial networks? Theoretical 550 Population Biology 64:473-480.

551 [20] Chaumot A, Charles S, Flammarion P, Auger P. 2003. Ecotoxicology and spatial 552 modeling in population dynamics: An illustration with brown trout. Environmental 553 Toxicology and Chemistry 22:958-969. 
554 [21] Emlen JM, Duda JJ, Kirchhoff MD, Freeman DC. 2006. Interaction Assessment: A 555 modeling tool for predicting population dynamics from field data. Ecological Modelling $556 \quad 192: 557-570$.

557 [22] Galic N, Baveco H, Hengeveld GM, Thorbek P, Bruns E, Van Den Brink PJ. 2012. 558 Simulating population recovery of an aquatic isopod: Effects of timing of stress and landscape 559 structure. Environmental Pollution 163:91-99.

560 [23] Van Den Brink PJ, Baveco JM, Verboom J, Heimbach F. 2007. An individual-based 561 approach to model spatial population dynamics of invertebrates in aquatic ecosystems after 562 pesticide contamination. Environmental Toxicology and Chemistry 26:2226-2236.

563 [24] Hansen F, Forbes VE, Forbes TL. 1999. Using elasticity analysis of demographic 564 models to link toxicant effects on individuals to the population level: an example. Functional 565 Ecology 13:157-162.

566 [25] Hanson N. 2009. Population level effects of reduced fecundity in the fish species 567 perch (Perca fluviatilis) and the implications for environmental monitoring. Ecological 568 Modelling 220:2051-2059.

569 [26] Hanson N, Stark JD. 2011. A comparison of simple and complex population models to 570 reduce uncertainty in ecological risk assessments of chemicals: example with three species of 571 Daphnia. Ecotoxicology:1-9. 
572 [27] Smit MGD, Kater BJ, Jak RG, van den Heuvel-Greve MJ. 2006. Translating bioassay

573 results to field population responses using a Leslie-matrix model for the marine amphipod

574 Corophium volutator. Ecological Modelling 196:515-526.

575 [28] McGee BL, Spencer M. 2001. A field-based population model for the sediment 576 toxicity test organism Leptocheirus plumulosus: II. Model application. Marine Environmental $577 \quad$ Research 51:347-363.

578 [29] Spencer M, McGee BL. 2001. A field-based population model for the sediment 579 toxicity test organism Leptocheirus plumulosus: I. Model development. Marine 580 Environmental Research 51:327-345.

581 [30] Pedersen S, Selck H, Salvito D, Forbes V. 2009. Effects of the polycyclic musk 582 HHCB on individual- and population-level endpoints in Potamopyrgus antipodarum. 583 Ecotoxicology and Environmental Safety 72:1190-1199.

584 [31] Gust M, Buronfosse T, Giamberini L, Ramil M, Mons R, Garric J. 2009. Effects of 585 fluoxetine on the reproduction of two prosobranch mollusks: Potamopyrgus antipodarum and 586 Valvata piscinalis. Environmental Pollution 157:423-429.

587 [32] Gust M, Garric J, Giamberini L, Mons R, Abbaci K, Garnier F, Buronfosse T. 2010. 588 Sensitivity of New Zealand mudsnail Potamopyrgus antipodarum (Gray) to a specific 589 aromatase inhibitor. Chemosphere 79:47-53. 
590 [33] Forbes VE, Moller V, Depledge MH. 1995. Intrapopulation variability in sublethal 591 response to heavy metal stress in sexual and asexual gastropod populations. Wiley592 Blackwell, Oxford.

593 [34] Møller V, Forbes VE, Depledge MH. 1996. Population responses to acute and chronic 594 cadmium exposure in sexual and asexual estuarine gastropods. Ecotoxicology 5:313-326.

595 [35] Gust M, Buronfosse T, Geffard O, Mons R, Queau H, Mouthon J, Garric J. 2010. In 596 situ biomonitoring of freshwater quality using the New Zealand mudsnail Potamopyrgus 597 antipodarum (Gray) exposed to waste water treatment plant (WWTP) effluent discharges. $598 \quad$ Water Research 44:4517-4528.

599 [36] Schmitt C, Vogt C, Van Ballaer B, Brix R, Suetens A, Schmitt-Jansen M, de Deckere 600 E. 2010. In situ cage experiments with Potamopyrgus antipodarum-A novel tool for real life 601 exposure assessment in freshwater ecosystems. Ecotoxicology and Environmental Safety $602 \quad 73: 1574-1579$

603 [37] Matthiessen P. 2008. An assessment of endocrine disruption in Mollusks and the 604 potential for developing internationally standardized mollusk life cycle test guidelines. 605 Integrated Environmental Assessment and Management 4:274-284.

606 [38] Jacobsen R, Forbes VE, Skovgaard O. 1996. Genetic population structure of the 607 prosobranch snail Potamopyrgus antipodarum (Gray) in Denmark using PCR-RAPD 608 fingerprints. Proceedings of the Royal Society B: Biological Sciences 263:1065-1070. 
609 [39] Mouthon J. 2001. Life cycle and population dynamics of the asian clam Corbicula

610 fluminea (Bivalvia: Corbiculidae) in the Rhône river at Creys-Malville (France). Anglais 151.

611 [40] Gust M, Buronfosse T, André C, Mons R, Gagné F, Garric J. 2011. Is exposure 612 temperature a confounding factor for the assessment of reproductive parameters of New 613 Zealand mudsnails Potamopyrgus antipodarum (Gray)? Aquatic Toxicology 101:396-404.

614 [41] Dorgelo J. 1987. Density fluctuations in populations (1982-1986) and biological 615 observations of Potamopyrgus Jenkinsi in two trophically differing lakes. Hydrobiological 616 Bulletin 21:95-110.

617 [42] Macken A, Le Page G, Hayfield A, Williams TD, Brown RJ. 2012. Effects of test 618 design and temperature in a partial life-cycle study with the freshwater gastropod 619 Potamopyrgus antipodarum. Environmental Toxicology and Chemistry 31:1989-1994.

620 [43] Winterbourn MJ. 1969. Water temperature as a factor limiting the distribution of 621 Potamopyrgus antipodum (Gastropoda Prosobranchia) in the New Zealand thermal region. 622 New Zealand Journal of Marine and Freshwater Research 3:453-458.

623 [44] Duft M, Schulte-Oehlmann U, Weltje L, Tillmann M, Oehlmann J. 2003. Stimulated 624 embryo production as a parameter of estrogenic exposure via sediments in the freshwater 625 mudsnail Potamopyrgus antipodarum. Aquatic Toxicology 64:437-449.

626 [45] Lefkovitch LP. 1965. The study of population growth in organisms grouped by stages. 627 Biometrics 21:1-18. 
628 [46] Caswell H, Shyu E. 2012. Sensitivity analysis of periodic matrix population models.

629 Theoretical Population Biology 82:329-339.

630 [47] Caswell H, Trevisan MC. 1994. Sensitivity analysis of periodic matrix models. 631 Ecology 75:1299-1303.

632 [48] Chaumot A, Charles S, Flammarion P, Garric J, Auger P. 2002. Using aggregation 633 methods to assess toxicant effects on population dynamics in spatial systems. Ecological 634 Applications 12:1771-1784.

635 [49] R Development Core Team. 2008. R: A Language and Environment for Statistical 636 Computing. R Foundation for Statistical Computing.

637 [50] Kerans BL, Dybdahl MF, Gangloff MM, Jannot JE. 2005. Potamopyrgus 638 antipodarum: Distribution, density, and effects on native macroinvertebrate assemblages in 639 the Greater Yellowstone Ecosystem. Journal of the North American Benthological Society $640 \quad 24: 123-138$.

641 [51] Schreiber ESG, Glaister A, Quinn GP, Lake PS. 1998. Life history and population 642 dynamics of the exotic snail Potamopyrgus antipodarum (Prosobranchia: Hydrobiidae) in 643 Lake Purrumbete, Victoria, Australia. Marine and Freshwater Research 49:73-78.

644 [52] Richards DC, Shinn DC. 2004. Intraspecific competition and development of size 645 structure in the invasive snail Potamopyrgus antipodarum (Gray, 1853). American Malacological Bulletin 19:33-37. 
647 [53] Quinn GP, Lake PS, Schreiber ESG. 1996. Littoral benthos of a Victorian lake and its

648 outlet stream: Spatial and temporal variation. Austral Ecology 21:292-301.

649 [54] Dahl A, Winther LB. 1993. Life-history and growth of the prosobranch snail 650 Potamopyrgus jenkinsi in Lake Esrom, Denmark. Verh Internat Verein Limnol 25:582-586.

651 [55] Sternberg RM, Gooding MP, Hotchkiss AK, LeBlanc GA. 2010. Environmental652 endocrine control of reproductive maturation in gastropods: Implications for the mechanism 653 of tributyltin-induced imposex in prosobranchs. Ecotoxicology 19:4-23.

654 [56] Ponder WF. 1988. Potamopyrgus antipodarum - A Molluscan coloniser of Europe and 655 Australia. Journal of Molluscan Studies 54:271-285.

656 [57] Moller V, Forbes VE, Depledge MH. 1994. Influence of acclimation and exposure 657 temperature on the acute toxicity of cadmium to the freshwater snail Potamopyrgus 658 antipodarum (hydrobiidae). Environmental Toxicology and Chemistry 13:1519-1524.

659 [58] Wallace C. 1979. Notes on the occurence of males in populations of Potamopyrgus 660 jenkensi. Journal of Molluscan Studies 45:61-67.

661 [59] Baird DJ, Brown SS, Lagadic L, Liess M, Maltby L, Moreira-Santos M, Schulz R, 662 Scott GI. 2007. In situ-based effects measures: determining the ecological relevance of 663 measured responses. Integrated environmental assessment and management 3:259-267. 
664 [60] Liber K, Goodfellow W, den Besten P, Clements W, Galloway T, Gerhardt A, Green 665 A, Simpson S. 2007. In situ-based effects measures: considerations for improving methods 666 and approaches. Integrated environmental assessment and management 3:246-258.

667 [61] Gust M, Buronfosse T, Geffard O, Coquery M, Mons R, Abbaci K, Giamberini L, 668 Garric J. 2011. Comprehensive biological effects of a complex field poly-metallic pollution 669 gradient on the New Zealand mudsnail Potamopyrgus antipodarum (Gray). Aquatic 670 Toxicology 101:100-108.

671 [62] Jensen A, Forbes VE, Parker Jr ED. 2001. Variation in cadmium uptake, feeding rate, 672 and life-history effects in the gastropod Potamopyrgus antipodarum: Linking toxicant effects 673 on individuals to the population level. Environmental Toxicology and Chemistry 20:25036742513.

675 [63] Biro PA, Post JR. 2008. Rapid depletion of genotypes with fast growth and bold 676 personality traits from harvested fish populations. Proceedings of the National Academy of 677 Sciences of the United States of America 105:2919-2922.

678 [64] Jørgensen C, Enberg K, Dunlop ES, Arlinghaus R, Boukal DS, Brander K, Ernande B, 679 Gårdmark A, Johnston F, Matsumura S, Pardoe H, Raab K, Silva A, Vainikka A, Dieckmann 680 U, Heino M, Rijnsdorp AD. 2007. Ecology: Managing evolving fish stocks. Science $681318: 1247-1248$. 


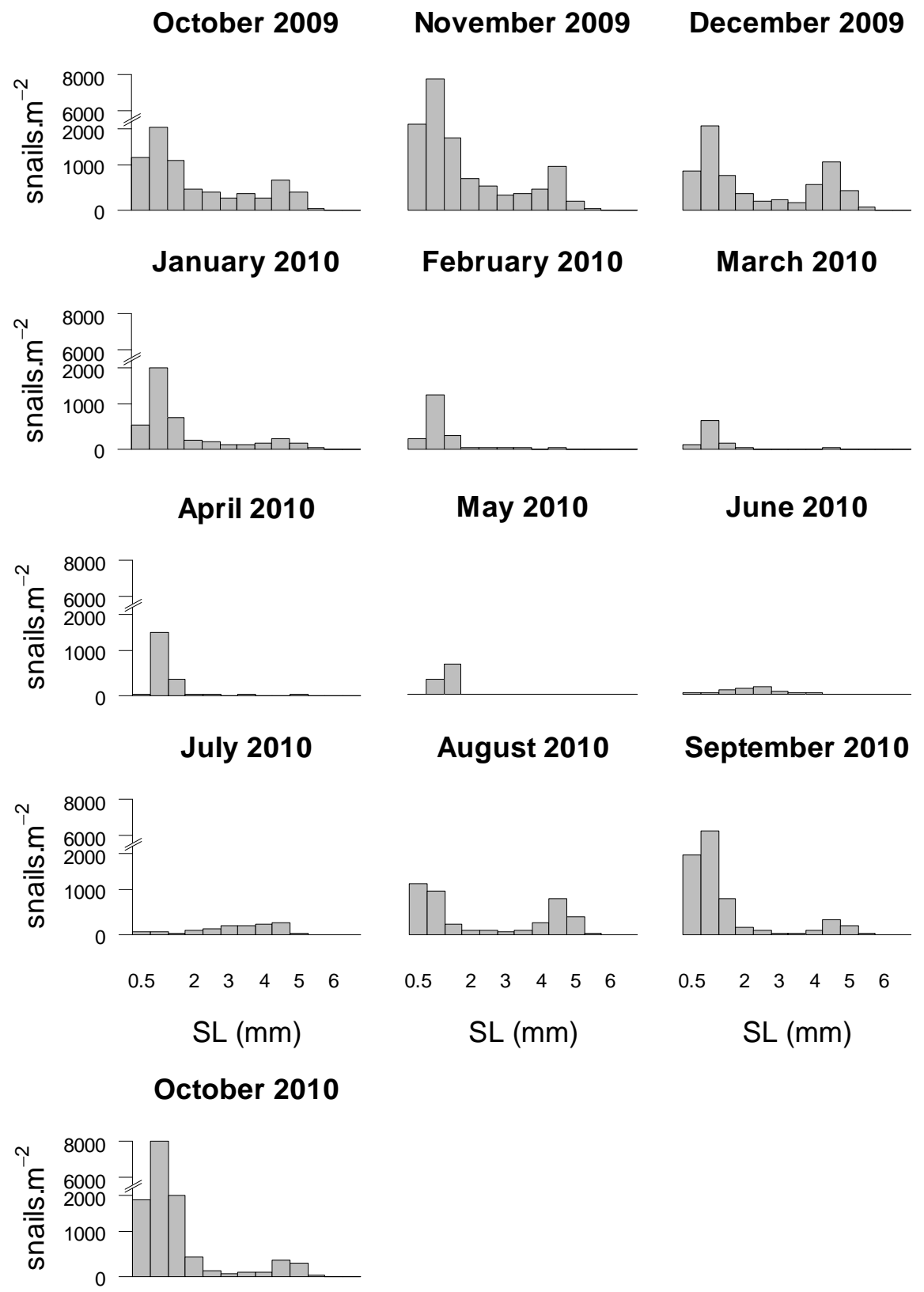

\section{Figure 1.}




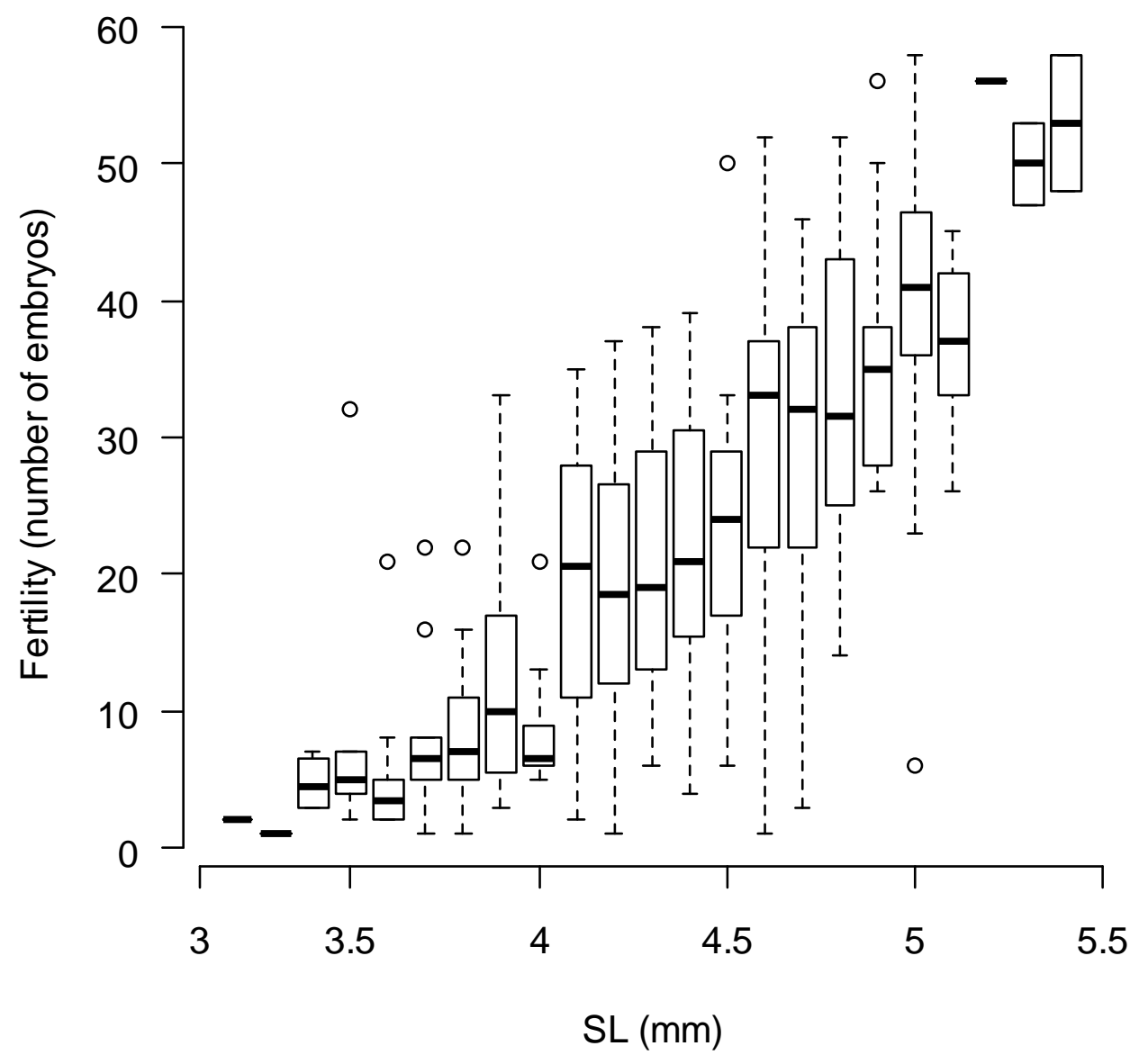

Figure 2. 

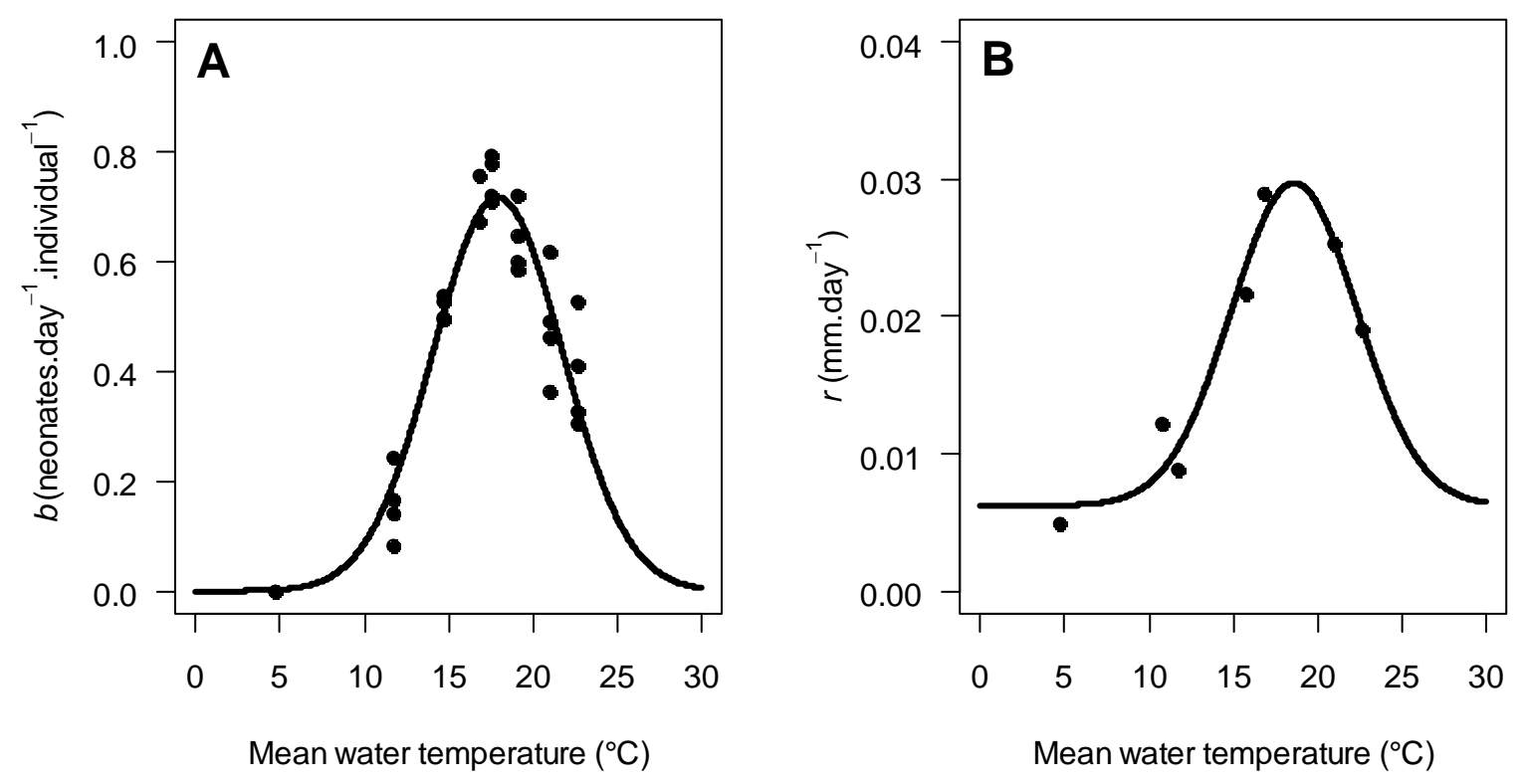

Figure 3. 
Author-produced version of the article published in Environmental Toxicology and Chemistry, vol. $32, n^{\circ} 8$, pp. $1727-1736$

The original publication is available at http://onlinelibrary.wiley.com/ doi : 10.1002/etc.2235 


$$
\text { I. I I I }
$$




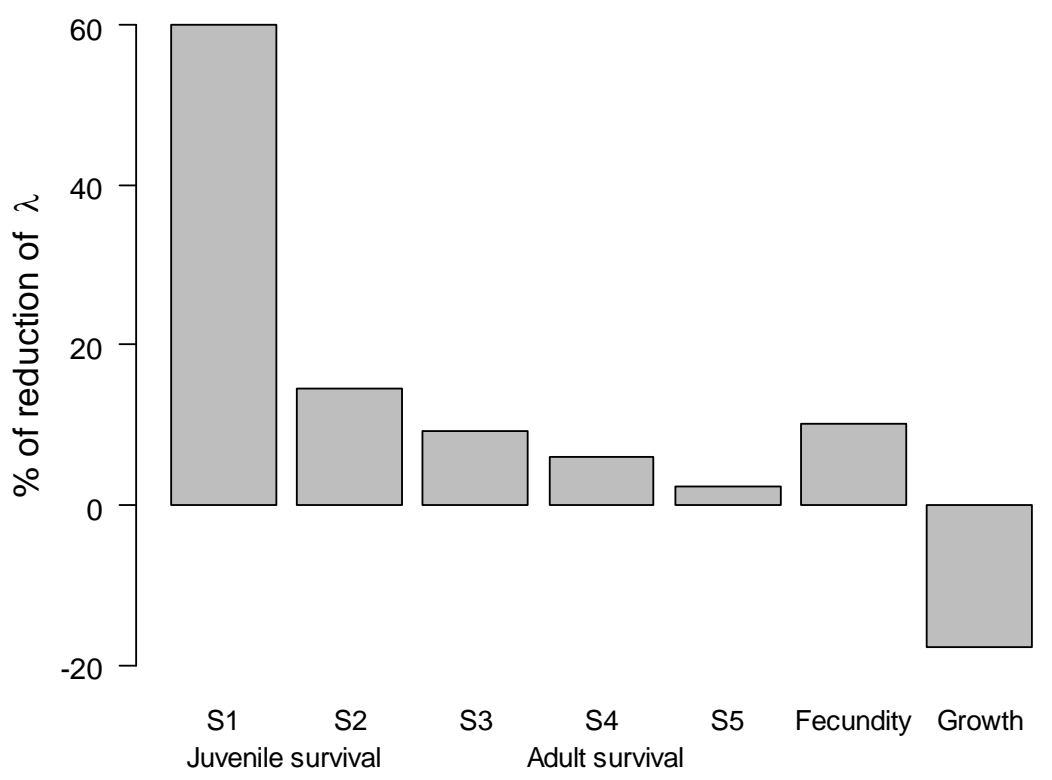

Figure 5. 


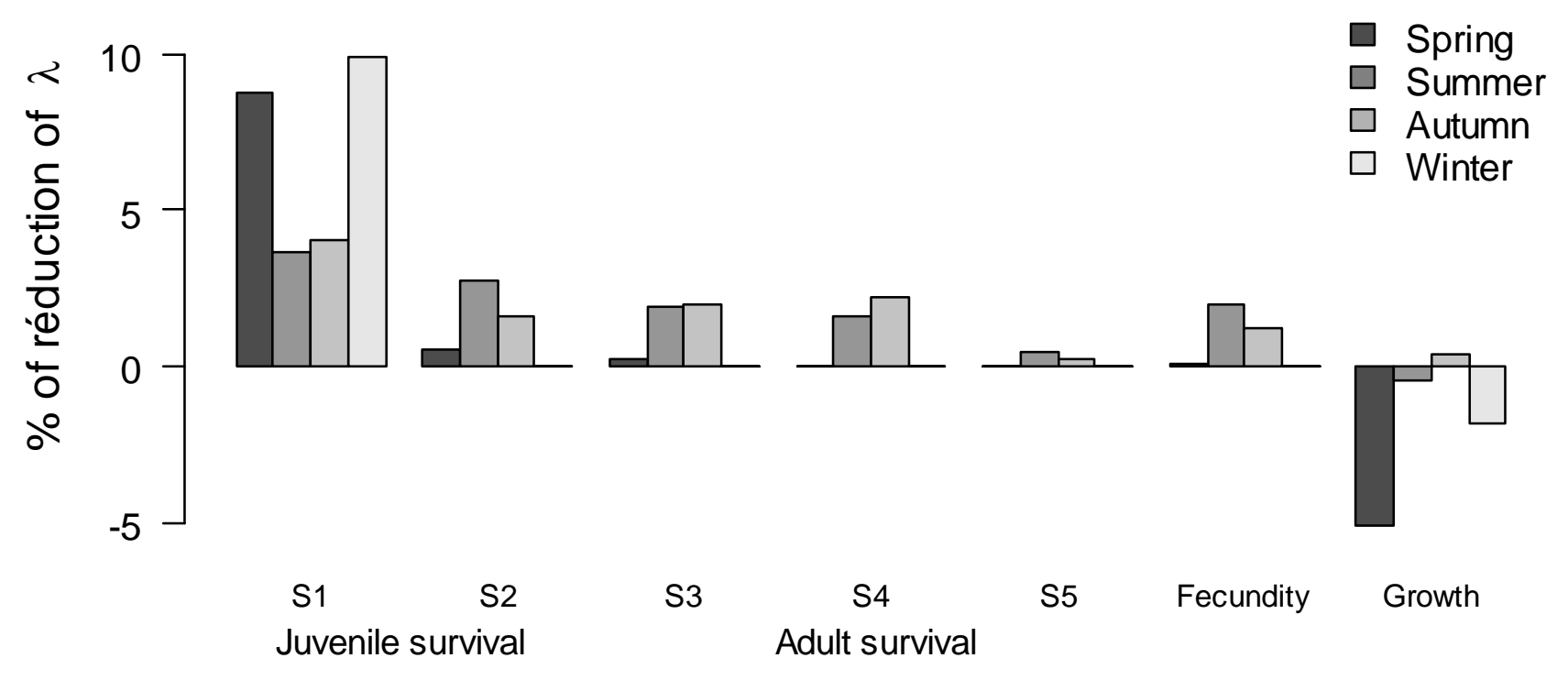

Figure 6. 
Author-produced version of the article published in Environmental Toxicology and Chemistry, vol. $32, n^{\circ} 8$, pp. $1727-1736$

The original publication is available at http://onlinelibrary.wiley.com/ doi : 10.1002/etc.2235 


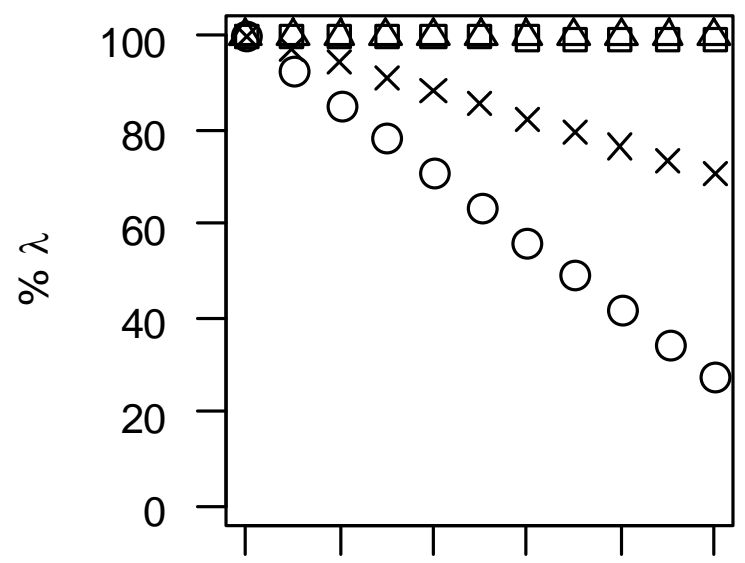

$\begin{array}{llllll}0 & 20 & 40 & 60 & 80 & 100\end{array}$

fecundity inhibition (\%)

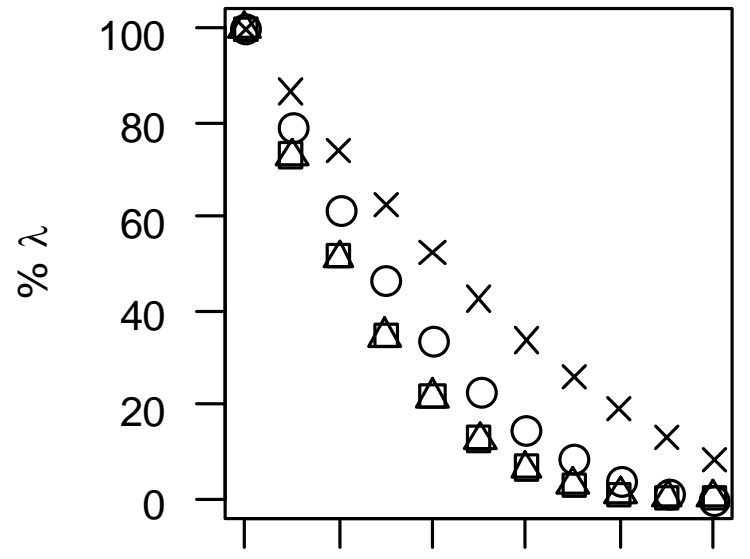

$\begin{array}{llllll}0 & 20 & 40 & 60 & 80 & 100\end{array}$

juvenile survival inhibition (\%)

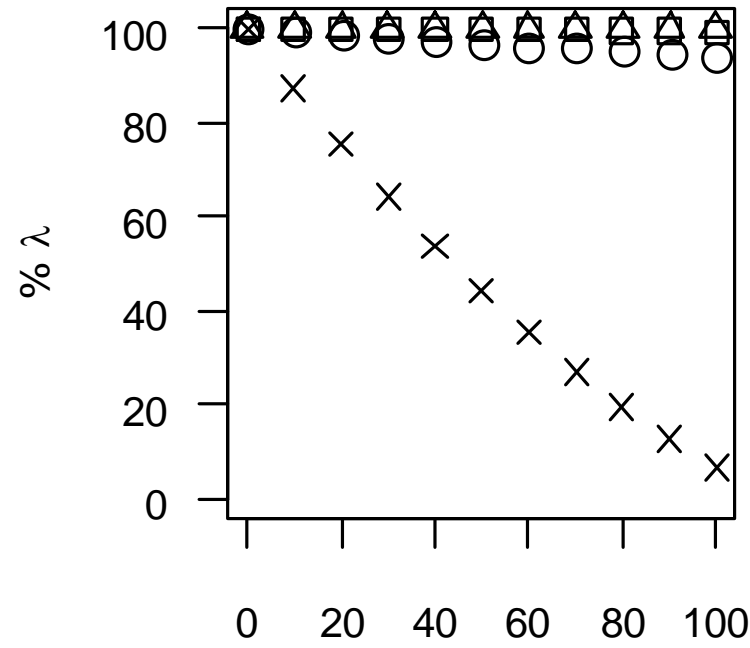

adult survival inhibition (\%)

$4 \quad$ Figure 7. 